\title{
Anti-Inflammatory Effects of FTY720 Do Not Prevent Neuronal Cell Loss in a Rat Model of Optic Neuritis
}

\author{
Christian R. Rau, ${ }^{*}$ Katharina Hein, ${ }^{*}$ \\ Muriel B. Sättler, ${ }^{*}$ Benedikt Kretzschmar, ${ }^{*}$ \\ Carina Hillgruber, ${ }^{*}$ Bradford L. McRae, ${ }^{\dagger}$ \\ Ricarda Diem, ${ }^{\ddagger}$ and Mathias Bähr* \\ From the Department of Neurology, University Medicine \\ Göttingen, Göttingen, Germany; the Department of \\ Pharmacology, ${ }^{\dagger}$ Abbott Bioresearch Center, Worcester, \\ Massachusetts; and the Department of Neurology, ${ }^{\ddagger}$ University of \\ the Saarland, Homburg/Saar, Germany
}

In multiple sclerosis, long-term disability is caused by axonal and neuronal damage. Established therapies target primarily the inflammatory component of the disease, but fail to prevent neurodegeneration. Fingolimod (codenamed FTY720) is an oral sphingosine 1-phosphate (S1P) receptor modulator with promising results in phase II trials in multiple sclerosis patients and is under further development as a novel treatment for multiple sclerosis. To evaluate whether FTY720 has neuroprotective properties, we tested this drug in a rat model of myelin oligodendrocyte glycoprotein-induced optic neuritis. FTY720 exerted significant anti-inflammatory effects during optic neuritis and reduced inflammation, demyelination, and axonal damage; however, FTY720 treatment did not prevent apoptosis of retinal ganglion cells (RGCs), the neurons that form the axons of the optic nerve. Consistent with this lack of effect on RGC survival, FTY720 treatment did not improve visual function, nor did it prevent apoptosis of RGCs in vitro. We observed a persistent activation of apoptotic signaling pathways in RGCs under FTY720 treatment, a possible underlying mechanism for the lack of neuroprotection in the presence of strong anti-inflammatory effects, Furthermore, FTY720 shifted the remaining inflammation in the optic nerve toward neurotoxicity by modest up-regulation of potential neurotoxic cytokines. We conclude that FTY720-induced anti-inflammation and axon protection did not of itself protect neurons from apoptotic cell death. (Am J Pathol 2011, 178:1770-1781; DOI: 10.1016/j.ajpath.2011.01.003)
Multiple sclerosis (MS) is an autoimmune disease of the central nervous system characterized by inflammation and demyelination. In MS and in its animal model, experimental autoimmune encephalomyelitis (EAE), axonal pathology occurs in the early phase and substantially contributes to disease severity. ${ }^{1-4}$ Although the contribution of axonal pathology to clinical disability is well recognized, all currently established therapies focus on the inflammatory component and lack long-term effects on brain atrophy and disability. Many patients who initially respond well to anti-inflammatory therapies continue to worsen over time and eventually convert to the secondary progressive phase of disease. Thus, there is urgent need to explore new therapeutic strategies that prevent axonal loss and apoptotic neuronal cell death.

The immunomodulator fingolimod (codenamed FTY720) is an oral sphingosine 1-phosphate (S1P) receptor agonist under development for the treatment of MS. It leads to selective lymphocyte retention in secondary lymphoid tissues, thereby preventing these cells from migrating into the central nervous system. Results of two phase III studies support phase II trial observations indicating that FTY720 exerts powerful anti-inflammatory effects in relapsing-remitting MS. ${ }^{5,6}$ Based on these promising results, FTY720 may become one of the first oral therapies approved for the treatment of relapsing-remitting MS.

FTY720 is a prodrug that is phosphorylated in vivo by sphingosine kinase 2 to produce the active metabolite, which functions as a high-affinity agonist at the S1P1-receptor and leads to long-term receptor down-regulation on lymphocytes. The therapeutic efficacy of oral FTY720 treatment has been demonstrated in various animal models of $\mathrm{MS}^{7-9}$ Beyond its role in trapping lymphocytes in lymphoid tissue, FTY720 has other pathophysiological effects; for example, it disrupts the blood-brain barrier and promotes glial repair mechanisms. ${ }^{10,11}$ Treatment with FTY720 even in a later stage of EAE resulted in improved visual function in

Supported by the European Union (FP6 program LSHM-CT-2005-018637, Neuropromise) and by Abbott USA.

C.R.R. and K.H. contributed equally to the present work.

Accepted for publication January 4, 2011

Address reprint requests to Dr. Katharina Hein, M.D., Neurologische Universitätsklinik, Robert-Koch-Str. 40, D-37075 Göttingen, Germany. E-mail: k.hein@uni-goettingen.de. 
dark agouti rats. ${ }^{12}$ However, neuroprotective effects of FTY720 have not been studied in detail, although these effects are most relevant for the long-term outcome in MS patients.

In the present study, we used an EAE model induced by myelin oligodendrocyte glycoprotein (MOG). MOGEAE is an established animal model of MS, closely replicating the pathogenic lesion formation of MS and including both the encephalitogenic T-cell response and the demyelinating autoantibody response. ${ }^{13,14}$ We had previously demonstrated that MOG-EAE induced in female brown Norway rats strongly reflects the neurodegenerative aspects of MS. Although the extent of spinal cord lesions in this model shows a certain variability, $90 \%$ of female brown Norway rats develop acute optic neuritis within 3 weeks after immunization with MOG, which leads to acute axonal degeneration of the optic nerve and consecutive apoptosis of retinal ganglion cells (RGCs), the neurons that form its axons. ${ }^{2,15,16}$ This EAE model provides a unique opportunity to investigate the morphological and functional changes in neuronal cell bodies during neurodegeneration of the optic nerve and is an excellent system for evaluating potential neuroprotective therapies. The aim of the present study was to elucidate whether FTY720 can prevent RGC degeneration in our animal model. We therefore combined the investigation of optic nerve histopathology with analyses of intracellular apoptotic signaling cascades in RGCs, electrophysiological recordings, and in vitro experiments in primary RGC cultures.

\section{Materials and Methods}

\section{Rats}

Female brown Norway rats $8-10$ weeks of age were used in all experiments. They were obtained from Harlan-Winkelmann (Borchen, Germany) and were kept under environmentally controlled, pathogen-free conditions. All experiments involving animal use were performed in accordance with the relevant laws and institutional guidelines. The experiments were approved by the local authorities in Braunschweig, Germany.

\section{Induction and Evaluation of EAE and Sham Immunization}

The rats were anesthetized by inhalation anesthesia with diethylether and injected intradermally at the base of the tail with a total volume of $200 \mu \mathrm{L}$ inoculum, containing 75 $\mu \mathrm{g}$ recombinant rat MOG'gd (kindly provided by C. Stadelmann and D. Merkler, Department of Neuropathology, Göttingen, Germany) in saline emulsified (1:1) with complete Freund's adjuvant (CFA; Sigma-Aldrich, St. Louis, MO) containing $200 \mu \mathrm{g}$ heat-inactivated Mycobacterium tuberculosis (strain H 37 RA; Difco Laboratories, Detroit, MI). Sham-immunized animals received Freund's adjuvant without MOG. Rats were scored for clinical signs of EAE and were weighed daily. The score reflects the quantity of spinal cord lesions; it does not include vision symptoms and does not correlate with the severity of optic neuritis. ${ }^{15,17}$ The signs were scored as follows: grade 0 , no symptoms; grade 0.5 , distal paresis of the tail; grade 1, complete tail paralysis; grade 1.5, paresis of the tail and mild hind limb paresis; grade 2.0, unilateral severe hind limb paresis; grade 2.5, bilateral severe hind limb paresis; grade 3.0, complete bilateral hind limb paralysis; grade 3.5 , complete bilateral hind limb paralysis and paresis of one front limb; grade 4, complete paralysis (tetraplegia), moribund state, or death.

At day 1 of clinically manifest EAE (or, in the absence of manifest disease, at day 19 after immunization), blood samples were taken sublingually. The analyses of the differential blood counts were performed in the Laboratory of University Hospital Göttingen.

\section{Systemic Treatment of Rats}

Animals were assigned into two treatment groups of 10 animals each. One group was treated daily by oral application of FTY720 (Abbott, Wiesbaden, Germany) in a concentration of $3 \mathrm{mg} / \mathrm{kg}$ body weight in $2 \%$ cyclodextrin starting on day 7 after immunization until day 8 after clinical manifestation of the disease (EAE day 8). Animals were weighed daily for dose calculation. The control group received vehicle only. Applications of FTY720 were continued until day 28 after immunization in the case of clinically healthy animals (ie, in the absence of clinical manifestation of disease). One group of 5 rats received daily combination therapy with FTY720 (3 mg/kg in 2\% cyclodextrin) and erythropoietin (Epo) for the same treatment protocol as the FTY720 monotherapy group. The Epo was applied intraperitoneally in the dosage of $5000 \mathrm{U} / \mathrm{kg}$ body weight in $1 \mathrm{~mL}$ $0.9 \% \mathrm{NaCl}$, which has been shown to be most effective in terms of neuroprotection in MOG-EAE. ${ }^{18}$ To exclude a possible neurotoxic effect of FTY720 on RGCs in vivo, 5 rats were sham-immunized with complete Freund's adjuvant and the FTY720 treatment ( $3 \mathrm{mg} / \mathrm{kg}$ body weight) was started at day 7 after immunization and continued until day 21 after immunization.

\section{Retrograde Labeling of RGCs}

Retrograde labeling of RGCs with Fluoro-Gold dye was performed by stereotactic application of the fluorescent dye to both superior colliculi 2 weeks before immunization, to avoid influences of axonal transport dysfunction. The brown Norway rats were anesthetized by intraperitoneal injection of ketamine (Ketanest 10; $0.65 \mathrm{~mL} / \mathrm{kg}$; Atarost, Twistringen, Germany) together with xylazine $2 \%$ $(0.35 \mathrm{~mL} / \mathrm{kg}$; Albrecht, Aulendorf, Germany) and positioned in a stereotaxic frame. The skin was incised mediosagittally, and holes were drilled into the skull above each superior colliculus $(6.8 \mathrm{~mm}$ dorsal and $2 \mathrm{~mm}$ lateral from bregma). We injected stereotactically $2 \mu \mathrm{L}$ FluoroGold dye (5\% in normal saline; Fluorochrome, Englewood, CO) into both superior colliculi.

\section{Electrophysiological Recordings}

At EAE day 8, rats were anesthetized by intraperitoneal injection of ketamine 10\% (Ketanest 10; $0.65 \mathrm{~mL} / \mathrm{kg}$; Ata- 
rost) together with xylazine $2 \%(0.35 \mathrm{~mL} / \mathrm{kg}$; Albrecht) and were positioned in a stereotaxic frame. Recordings of visual evoked potentials (VEPs) were performed with surface electrodes attached to the scalp; electroretinography was performed as described previously. ${ }^{2}$ Visual stimuli were presented on a 17-inch video monitor ( $\sim 43 \mathrm{~cm}$ diagonal) positioned $20 \mathrm{~cm}$ in front of the eye. The display was centered in a position approximately 40 degrees medially from the pupil axis. The rat eye is known to be emmetropic, and has large depth of focus because of the pinhole pupil. ${ }^{19}$ Light flashes $20 \mu$ s in duration were used at a rate of $1 \mathrm{~Hz}$, and bar stimulation consisted of vertical gratings of variable spatial frequency, alternating in phase with a temporal frequency of $1.8 \mathrm{~Hz}$. In each animal, electroretinographic potentials in response to flash and VEP potentials in response to flash, to pattern stimulation of 6 and 10 alternating bars, and to pattern stimulation of a 5-cm checkerboard pattern were analyzed at day 8 of clinically apparent disease. All potentials were analyzed by Sigma CX software version 2.81 (Sigma Medizintechnik, Thum, Germany). Clear potentials to different stimulation were given a score: $1=$ flash; $2=6$ alternating bars; $3=10$ alternating bars; and $4=$ checkerboard. Immediately after the end of the recording session, the rats received an overdose of carbon dioxide and were perfused via the aorta with $4 \%$ paraformaldehyde in PBS. Six sham-immunized animals were sacrificed for analysis on day 28 after immunization.

\section{Histopathology and Immunohistochemistry}

The retinas were removed for counting RGCs; optic nerves (ONs) were taken for histopathological evaluation and were paraffin-embedded. Histological evaluation was performed on 4- $\mu$ m-thick slices stained with Luxol Fast Blue and Bielschowsky's silver impregnation to assess demyelination and axonal pathology. Photos of vertical sections were taken using an AxioCam MR microscopy camera (Zeiss, Göttingen, Germany). The images were processed using Zeiss AxioVision 4.2 software to evaluate the demyelinated area as a percentage of the entire ON cross-section. The density of axons in each $\mathrm{ON}$ was measured in at least three standardized microscopic fields (2500 $\mu \mathrm{m}^{2}$ each). Mean axon density was calculated for each ON. Immunohistochemistry was performed on paraffin sections. ED-1 ${ }^{+}$macrophages/activated microglia (MCA341R diluted 1:500; Serotec, Oxford, UK), $\beta$-amyloid precursor protein-positive $\left(\mathrm{APP}^{+}\right.$) axons (MAB348 diluted 1:3000; Chemicon, Ford, UK), $\mathrm{CD}^{+}$T-lymphocytes (diluted 1:500; Biozol Diagnostica, Eching, Germany) and sphingosine-1-phosphate1(S1P1)-receptor (diluted 1:500; ZYTOMED Systems, Berlin, Germany) were detected in ON cross-sections using biotin-avidin detection. S1P1-receptor was additionally investigated in the retina. Spleen sections served as a control for ED-1 and CD3 stainings. The evaluation of $\mathrm{ED}-1^{+}$and $\mathrm{CD}^{+}$cells was according to the following scale: $0=$ no labeled cells; $1=$ a few positive cells in at least one of three different ON levels; $2=10 \%-50 \%$ of at least one ON cross-section infiltrated with labeled cells, and $3=>50 \%$ of the ON cross-section infiltrated with labeled cells in at least one ON level. The number of $\beta$-APP ${ }^{+}$axons was counted in three different ON sec- tions. To evaluate chronic axonal damage, we analyzed the axonal density in cross-sections of ONs by Bielschowsky's silver impregnation and compared them with the density of healthy controls. The investigators who performed neuropathological examinations were blinded to the treatment applied (C.R.R. and M.B.S.).

DNA fragmentation of cells undergoing apoptosis was analyzed by the TUNEL method (ie, terminal deoxynucleotidyl transferase-mediated biotinylated UTP nick end labeling) on the paraffin sections of the retina of vehicle and FTY720-treated animals as described previously. ${ }^{2}$

\section{Quantification of RGC Density}

Retinas were dissected, flat-mounted on glass slides, and examined by fluorescence microscopy (Zeiss Axioplan 2) using a DAPI filter (315/395 nm). Retinal ganglion cell densities were determined by counting labeled cells in three areas $\left(62,500 \mu \mathrm{m}^{2}\right.$ each) per retinal quadrant at three different eccentricities of $1 / 6,3 / 6$, and $5 / 6$ of the retinal radius. Cell counts were performed by two independent investigators according to a blinded protocol (C.R.R. and K.H.).

\section{Western Blot}

On EAE day 1 or on day 19 after immunization in the absence of manifest disease, retinas were homogenized and lysed ( $n=13$ for vehicle- or FTY720-treated animals; $150 \mathrm{mmol} / \mathrm{L} \mathrm{NaCl}, 50 \mathrm{mmol} / \mathrm{L}$ Tris, $\mathrm{pH} 8.0,2 \mathrm{mmol} / \mathrm{L}$ EDTA, and $1 \%$ Triton, containing $0.1 \mathrm{mmol} / \mathrm{L}$ phenylmethylsulfonyl fluoride and $2 \mu \mathrm{g} / \mathrm{mL}$ pepstatin, leupeptin, and aprotinin) on ice for 20 minutes. The rationale for this investigation time point was based on our previous results, which showed that the most prominent changes in the intracellular signaling cascade occur in the early phase of the disease. ${ }^{16}$

Cell debris was pelleted by centrifugation at 13,000 $\times$ $g$ for 15 minutes, and protein concentration of the supernatant was determined using a Pierce BCA protein assay (Thermo Fisher Scientific, Rockford, IL). The lysates (40 $\mu \mathrm{g}$ of protein per lane; $n=4$ for each group) were separated by reducing SDS-polyacrylamide gel electrophoresis, and proteins were transferred to a polyvinylidene difluoride membrane and blocked with 5\% nonfat milk in $0.1 \%$ Tween 20 in PBS (PBS-T). After incubation with the primary antibody against phosphoAkt (9271; New England Biolabs, Schwalbach, Germany; 1:1000 in 1\% nonfat milk in PBS-T), Akt (9272; New England Biolabs; $1: 1000$ in 5\% nonfat milk), Bax (sc-526; Santa Cruz Biotechnology, Santa Cruz, CA; 1:1000 in 5\% nonfat milk in PBS-T), or phospho-MAPK 1 and 2 (9106, New England Biolabs; 1:200 in 1\% nonfat milk in PBS-T), membranes were washed in PBS-T and incubated with horseradish peroxidase (HRP)-conjugated secondary antibodies against rabbit IgG (Santa Cruz Biotechnology; $1: 2500$ in $1 \%$ nonfat milk). For Western blot analysis of Bcl-2 levels sc-7382 (Santa Cruz Biotechnology; 1:200 in $5 \%$ nonfat milk) and HRP-conjugated secondary antibody against mouse IgG was used (Santa Cruz, Biotechnology; 1:2000 in 1\% nonfat milk in PBS-T). MAPK 1 and 2 protein 
levels were detected using a primary antibody (Sc-93-G; Santa Cruz Biotechnology) diluted 1:500 in 1\% nonfat milk in PBS-T and a HRP-conjugated secondary antibody against goat IgG (Santa Cruz; 1:10000 in PBS-T). Nitrotyrosine protein concentration was detected using a primary antibody (ab7048; Abcam, Cambridge, UK) diluted 1:1000 in $1 \%$ nonfat milk in PBS-T and a HRP-conjugated secondary antibody against mouse IgG (Santa Cruz Biotechnology, Santa Cruz, CA; 1:1000 in PBS-T). For Western blot analysis of $\beta$-tubulin as a housekeeping protein, the primary antibody (Sigma-Aldrich) was diluted 1:1000 in TBS-T. Secondary antibody against mouse IgG (Santa Cruz Biotechnology; 1:2000 in 5\% nonfat milk) was applied.

Labeled proteins were detected using Amersham ECLplus reagent (GE Healthcare, Piscataway, NJ). Developed films were scanned and band densitometry was done using ImageJ software version 1.41 ( $\mathrm{NIH}$, Bethesda, MD). The process included background subtraction and normalization.

\section{Enzyme-Linked Immunosorbent Assay and Luminex Assay}

Samples of the ON were obtained on day 1 of clinical manifestation of the disease (EAE day 1) or day 19 after immunization in the absence of manifest disease. To determine the levels of interleukin-12 (IL-12), transforming growth factor- $\beta 1$ (TGF- $\beta 1$ ), and tumor necrosis factor- $\alpha$ (TNF- $\alpha$ ) in the ON, an enzyme-linked immunosorbent assay technique was used. For each cytokine, an ELISA kit (R\&D Systems, Minneapolis, MN) was used according to the manufacturer's instructions. Wells of a 96-well polystyrene microtiter plate were coated with the recombinant antibody, ON samples were applied and were washed several times before incubation with the respective HRPconjugated IgG polyclonal antibodies. After washing and addition of substrate, the absorbance was read at 450 $\mathrm{nm}$. To obtain a standard curve, the E. coli expressed Quantikine M rat kit (R\&D Systems) standard was used.

For multiplexed quantification of cytokines in the ON protein lysates (obtained on day 1 of clinical disease or on day 19 after immunization in the absence of manifest disease; $n=13$ each group), we used color-coded, bead-based Luminex assays (R\&D Systems). For intercellular adhesion molecule-1(ICAM-1), IL-1 $\beta, I L-18$, and tissue inhibitor of metalloprotease-1 (TIMP-1), commercially available kits [Fluorokine multianalyte profiling (MAP) rat base kits; R\&D Systems ] were used, according to the manufacturer's instructions.

Both enzyme-linked immunosorbent assay and Luminex assays were repeated twice, with similar results observed.

\section{Cell Culture}

FTY720 is phosphorylated by sphingosine kinase (SphK) in vivo to FTY720-phosphate ${ }^{20,21}$ and behaves as a full agonist on S1P1, S1P4, and S1P5 receptors. In the present study, we investigated the effect of the active phosphorylated form of FTY720 ( $\mathrm{pFTY720)} \mathrm{in} \mathrm{vitro.} \mathrm{Primary} \mathrm{RGCs} \mathrm{were}$ obtained from 7- to 9-day-old Sprague-Dawley rats as de- scribed previously. ${ }^{22}$ Isolated RGCs were distributed in a density of 10,000 RGCs per well on a 96-well microtiter plates coated with poly-D-lysine and laminin for better adhesion. All cells were kept at $37^{\circ} \mathrm{C}$ and $5 \% \mathrm{CO}_{2}$ in medium containing glutamate, L-cysteine, B27-supplement, natrium pyruvate, triiodothyronine, and Sato's medium (transferrin, bovine serum albumin, progesterone, putrescine). Neurotrophic factors brain-derived neurotrophic factor (BDNF), ciliary neurotrophic factor (CNTF), insulin, and forskolin were added to one group of cells (+GF). PFTY720 was added in different concentrations $(0,0.1,1,5,10$, and 30 $\mu \mathrm{mol} / \mathrm{L}$ ), followed by incubation for 24 hours at $37^{\circ} \mathrm{C}$ and $5 \% \mathrm{CO}_{2}$. Cell viability was assessed using an MTT assay [0.5 mg/mL 3-(4,5-dimethylthiazol-2-yl)-2,5'-diphenyltetrazolium bromide per well] by counting the number of surviving cells in six fields of view in each of three wells per concentration and was performed on three separate cell preparations, to ensure reliability of the data. Data are presented as a percentage of controls.

\section{Statistical Analyses}

Except as noted, data are reported as means \pm SEM. Student's $t$-test was used to assess RGC densities, inflammatory infiltration, demyelination, axonal densities within the ONs, and electrophysiological function. A $P$ value of $<0.05$ was considered to be statistically significant. One-way analysis of variance followed by Bonferroni correction was used for multiple group comparison.

\section{Results}

\section{Clinical Disease Course Is Improved by FTY720}

FTY720 was given orally in a daily dosage of $3 \mathrm{mg} / \mathrm{kg}$. Treatment of the rats was started 1 week after immunization with MOG, to avoid interference with the initiation of the immune response. Disease incidence was substantially reduced in the animals treated with FTY720. In this group, only 2 of the 10 animals developed clinical manifestations of

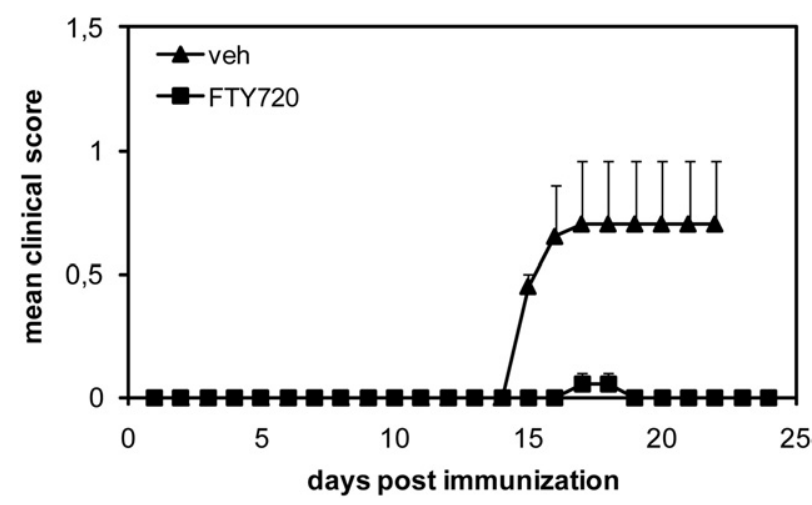

Figure 1. Clinical score. Daily oral application of FTY720 started at day 7 after immunization significantly suppresses incidence of MOG-EAE. Severity of disease was also substantially reduced. Mean clinical score under treatment with FTY720 during disease course was compared with vehicle-treated animals ( $n=10$ for each group); all animals are included, with or without clinical symptoms. The clinical score represents primarily spinal cord lesions; visual function is not included. 
Table 1. Significant Reduction of Leukocytes, Lymphocytes, and Neutrophils in Peripheral Blood under FTY720 Treatment

\begin{tabular}{cccccc}
\hline Animal group & $\begin{array}{c}\text { Leucocytes } \\
\left(10^{3} / \mu \mathrm{L}\right)\end{array}$ & $\begin{array}{c}\text { Erythrocytes } \\
\left(10^{3} / \mu \mathrm{L}\right)\end{array}$ & $\begin{array}{c}\text { Thrombocytes } \\
\left(10^{3} / \mu \mathrm{L}\right)\end{array}$ & $\begin{array}{c}\text { Lymphocytes } \\
\left(10^{3} / \mu \mathrm{L}\right)\end{array}$ & $\begin{array}{c}\text { Neutrophils } \\
\left(10^{3} / \mu \mathrm{L}\right)\end{array}$ \\
\hline FTY720 & $2.21 \pm 1.01$ & $8.25 \pm 0,48$ & $702 \pm 154.82$ & $1.049 \pm 0.49$ & $0.716 \pm 0.23$ \\
Vehicle & $10.13 \pm 2.52$ & $7.79 \pm 1.97$ & $751.5 \pm 201.92$ & $8.37 \pm 2.16$ & $1.173 \pm 0.25$ \\
$P$ value & $<0.0001^{*}$ & 0.5267 & 0.5908 & $<0.0001^{*}$ & $0.0026^{*}$ \\
\hline
\end{tabular}

The blood analysis was performed on day 1 of disease in a rat model of multiple sclerosis: experimental autoimmune encephalomyelitis induced by myelin oligodendrocyte glycoprotein (MOG-EAE).

Data are reported as means \pm SEM $(n=8)$.

${ }^{*} P<0.05$ is considered to be statistically significant.

MOG-EAE, whereas 9 of the 10 vehicle-treated animals showed clinical signs of EAE. In both treatment groups, symptoms started to develop at approximately day 14 after immunization as a typical characteristic of MOG-EAE. During the disease course, none of the FTY720-treated animals progressed beyond grade 0.5 , and in the diseased animals neurological deficits declined within 2 days. At the end of the experiment (EAE day 8), none of the FTY720-treated animals showed clinical signs of EAE; however, optic neuritis was present, as evidenced by VEPs and histopathological evaluations. In contrast, the mean clinical score in the 10 vehicle-treated animals reached $0.7 \pm 0.2$ (Figure 1). Clinical experiments were repeated with 13 animals per group, and similar results concerning incidence and severity of the disease were observed.

Blood samples taken at day 1 of clinically manifest EAE or at day 19 after immunization in the absence of manifest disease showed a significant reduction of leukocytes $\left(2.21 \pm 1.01 \times 10^{3} / \mu \mathrm{L}\right.$ in the FTY720 group, compared with $10.13 \pm 2.52 \times 10^{3} / \mu \mathrm{L}$ in the vehicle-treated group; $P<0.0001$ ), whereas counts for erythrocytes and thrombocytes remained unchanged. In the white blood cell count, the reduction of lymphocytes $(P<0.001)$ under FTY720 was greater than the reduction of neutrophils $(P<0.01)$, as a result of the inhibition of lymphocyte circulation by FTY720 23 (Table 1).

\section{Electrophysiological Recordings Are Unchanged}

To evaluate the influence of FTY720 on the electrophysiological function of the optic system, we performed VEP and electroretinographic recordings in both animal groups at EAE day 8 , or at day 28 after immunization in the absence of manifest disease. Sham-immunized animals served as the positive control (Figure 2A). Visual evoked potentials can be used to estimate the function of the ON. Electroretinograms in response to flash stimulation represent the activity of all retinal neurons and were used as a positive control for our electrophysiological measurements. 2,24 The two eyes were analyzed separately in each animal. Visual function as determined by flash and pattern VEP recordings was severely impaired in both rat groups, with no statistically significant difference $(P=0.91466$; Figure 2D). In contrast to the clinical

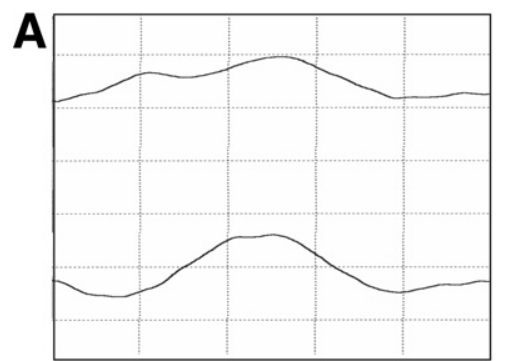

B
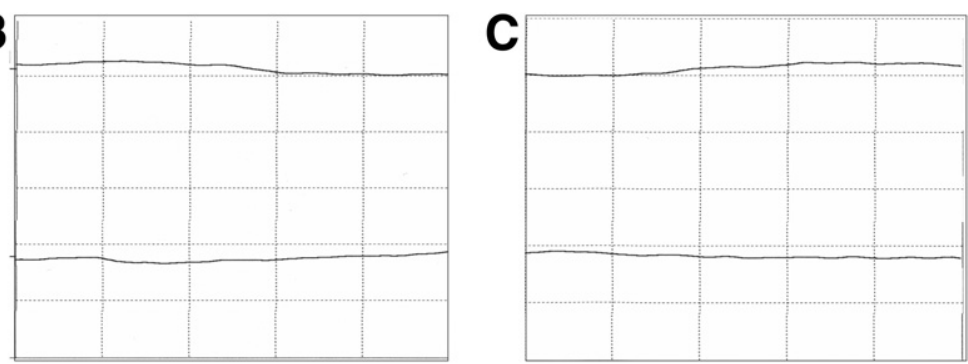

D

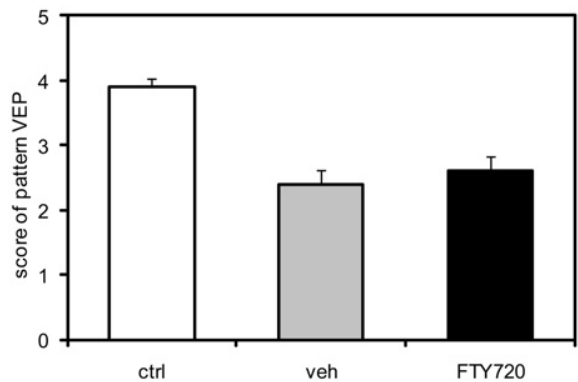

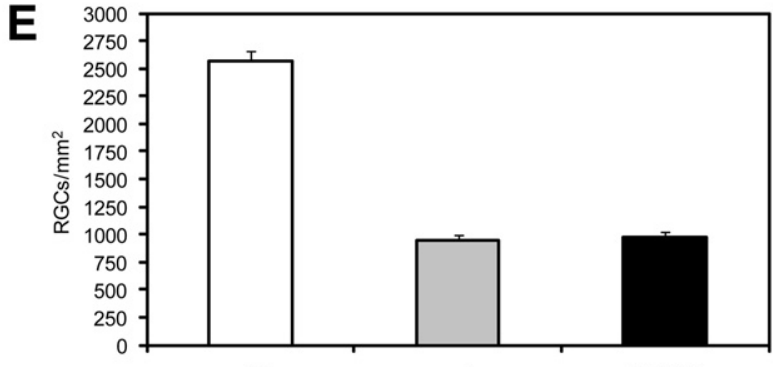

ctrl veh

FTY720

Figure 2. Visual evoked potentials (VEP) and RGC survival. Electrophysiological measurement of the visual system at day 28 after immunization showed no improvement in VEP recordings in FTY720-treated animals, compared with vehicle-treated controls. A-C: Representative pattern VEP recordings of the left eye and the right eye of a sham-immunized control animal (A), FTY720-treated animal (B), and a vehicle-treated animal (C). D: Mean VEP score was 3.8 in the control rats immunized with complete Freund's adjuvant (ctrl), 2.4 in the vehicle group, and 2.6 in the FTY720-treated group $(n=10$ in each group; $P=0.91466$ for FTY720- vs. vehicle-treated animals). E: Mean density of RGCs in sham-immunized control (ctrl), FTY72-treated, and vehicle-treated animals at 28 days after immunization. There was no significant difference in RGC survival between the FTY720 treatment and vehicle treatment groups $(P=0.71256)$. 
A
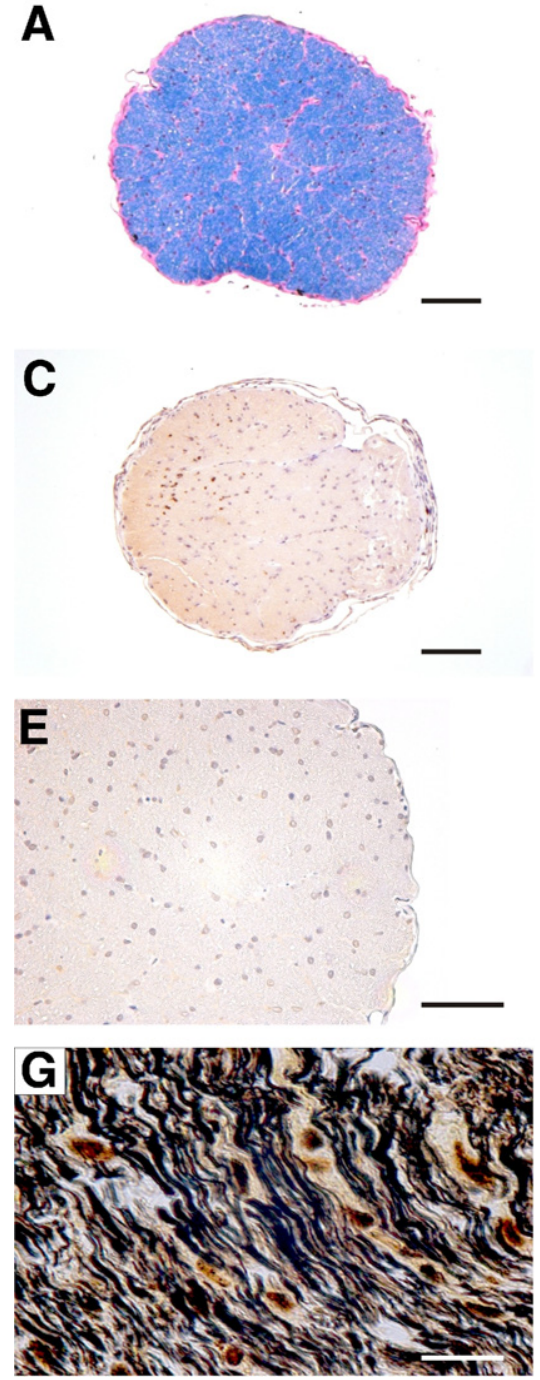

B

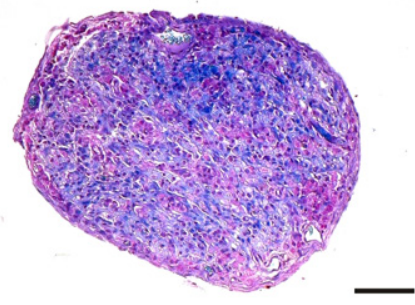

D
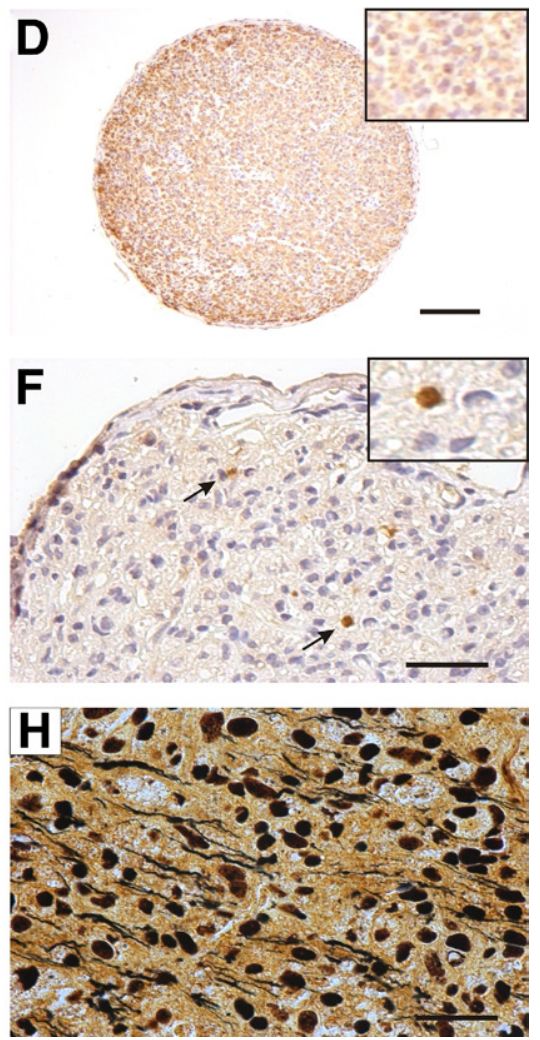

Figure 3. Optical nerve (ON) histopathology. A and B: Representative Luxol Fast Blue-stained cross-section of ONs of an FTY720-treated rat (A) shows only small areas of demyelination, with mainly intact myelin (blue); in contrast, a cross-section from a vehicle-treated control animal (B) shows extensively demyelinated areas (purple). C and D: Representative examples of the substantially higher number of ED1 ${ }^{+}$macrophages/activated microglia detected in the ON of a vehicle-treated control animal (D), compared with an animal that had received FTY720 (C). Inset: Higher-magnification view of ED $1^{+}$cells. E and F: Representative ON cross-sections showing reduced $\beta$-APP ${ }^{+}$axons (arrows) under FTY720 treatment on EAE day 8 (E), compared with the vehicle-treated control (F). Appearance on day 28 after immunization was essentially the same as shown here (E) for day 8 of MOG-EAE. F, Inset: Higher-magnification view of a $\beta$-APP ${ }^{+}$ axon. G and H: Bielschowsky's silver impregnation of an ON cross-section reveals different densities of axons on EAE day 8 in FTY 720 -treated animals (G) and vehicle-treated control animals (H). Scale bars: $100 \mu \mathrm{m}(\mathbf{A}-\mathbf{F}) ; 20 \mu \mathrm{m}(\mathbf{G}$ and $\mathbf{H})$.

score, visual function in the rats was not improved by treatment with FTY720.

\section{FTY720 Treatment Reduces Neuropathological Damage of the Optic Nerve}

At day 8 of clinical disease or at day 28 after immunization in the absence of manifest disease, we determined the extent of demyelination of the ONs by Luxol Fast Blue staining. Additionally, we performed immunohistochemistry for $\mathrm{ED}-1^{+}$macrophages/microglia and $\mathrm{CD}^{+}{ }^{+}$T-lymphocytes to assess the extent of inflammatory infiltration. Acute and chronic axonal damage was assessed by immunohistochemistry for $\beta$-APP and by Bielschowsky's silver impregnation, respectively. For each staining, ON cross-sections of three different levels were evaluated. Representative examples are shown in Figure 3.

In analyzing the Luxol Fast Blue-stained ONs, we calculated the percentage of the demyelinated area with respect to the area of each ON cross-section. In FTY720treated animals, we observed significantly less demyelination within ON cross-sections at day 28 after immunization, compared with vehicle-treated controls $(P=$ 0.00173; Figure 3, A and B, and Table 2).

Analysis of inflammatory infiltration by ED1 staining revealed a substantially lower rate of infiltration by macrophages and activated microglia in the FTY720-treated animal group, compared with the control group $(P<$ 0.0001; Figure 3, C and D, and Table 2). Quantification of $\mathrm{CD}^{+}$cells revealed that only a minority of infiltrating cells were $\mathrm{CD}^{+}{ }^{+}$T-lymphocytes. At day 28 after immuni- 
Table 2. Histopathological Changes under FTY720 Treatment

\begin{tabular}{cccccc}
\hline Animal group & Demyelination $(\%)$ & Score of ED1 ${ }^{+}$cells & Score of CD3 ${ }^{+}$cells & $\beta$-APP ${ }^{+}$axons & Axon density $(\%)$ \\
\hline FTY720 & $6.54 \pm 1.98$ & $0.27 \pm 0.06$ & $0.04 \pm 0.19$ & $0.02 \pm 0.017$ & $98.11 \pm 0.55$ \\
Vehicle & $38.65 \pm 8.43$ & $1.63 \pm 0.24$ & $0.58 \pm 1.05$ & $1.65 \pm 0.52$ & $72.85 \pm 7.30$ \\
$P$ value & $0.00173^{*}$ & $<0.0001^{*}$ & $0.03649^{*}$ & $0.00709^{*}$ & $0.003^{*}$ \\
\hline
\end{tabular}

Analysis was performed on day 8 of MOG-EAE.

Data are reported as means $\pm \operatorname{SEM}(n=20)$.

${ }^{\star} P<0.05$ is considered to be statistically significant.

zation, different quantities of $\mathrm{CD}^{+}$cells were observed in both animal groups ( $P=0.03649$; Table 2). Acute axonal damage in ON cross-sections was evaluated using $\beta$-APP immunohistochemistry. At day 28 after immunization, the number of $\beta$-APP ${ }^{+}$axons per ON crosssection was significantly reduced in the FTY720-treated group, compared with the control group $(P=0.00709$; Figure 3, E and F, and Table 2). Using Bielschowsky's silver impregnation, we observed a beneficial effect of FTY720 on axonal survival at day 28 after immunization, compared with the vehicle-treated group $(P=0.003$; Figure 3, $\mathrm{G}$ and $\mathrm{H}$, and Table 2).

\section{FTY720 Reduces Accumulation of Oxidative Stress in Autoimmune Optic Neuritis}

Oxidative stress has been shown to contribute to neurodegeneration during autoimmune inflammation. Evidence for the existence of oxidative stress in autoimmune inflammation includes the presence of nitrotyrosine. ${ }^{25,26}$ Analysis of nitrotyrosine expression indicated a significantly reduced level of nitrotyrosine in the ON under FTY720 treatment, compared with the vehicle-treated animals $(P=0.003$ ) (Figure 4, B and C); however, FTY720 treatment did not have any influence on the nitrotyrosine concentration in the retina, compared with the vehicletreated animals $(P=0.22)$ (Figure 4A).

\section{Retinal Ganglion Cell Counts}

Based on the electrophysiological results indicating no detectable improvement of visual function after FTY720 therapy, we investigated the effect of FTY720 treatment on RGC survival. At day 28 after immunization with $M O G$, we compared retrograde labeling of RGCs in FTY720treated rats compared with vehicle-treated controls. At this time point, we observed similar RGC densities in both rat groups (941.94 \pm 52.97 per $\mathrm{mm}^{2}$ in vehicle-treated animals and $980.5 \pm 44.66$ per $\mathrm{mm}^{2}$ in FTY720-treated animals; $n=20$ per group; $P=0.71256$; Figure $2 \mathrm{E}$ ). These results indicate that oral application of $3 \mathrm{mg} / \mathrm{kg}$ per day of FTY720 does not exert a neuroprotective effect on RGCs in MOG-induced optic neuritis, although a prominent effect on inflammation and axon preservation in the ON was detected. We had previously reported that Epo treatment as a monotherapy and as an add-on therapy to methylprednisolone protects RGCs from secondary cell death. ${ }^{18,27}$ The rationale for combination therapy with both FTY720 and Epo was to investigate whether FTY720 treatment has synergistic effects on RGC survival after additional application of Epo. In the present study, additional daily application of Epo to FTY720 led to substantial survival of RGCs, compared with FTY720 therapy alone $\left(1638 \pm 106.46\right.$ cells $/ \mathrm{mm}^{2}$ for combined treatment; $P<$ $0.0001 ; n=10)$, a level that lies in the same range as for Epo therapy alone (1506/mm² for Epo monotherapy). ${ }^{18}$

\section{Differences in the Expression Pattern of the S1P1 Receptor}

To investigate the mechanism or mechanisms underlying the lack of neuroprotection despite substantial improvement of ON histopathology after application of FTY720, we evaluated the expression of the S1P1 receptor on retina, $\mathrm{ON}$, and spinal cord sections of healthy and $\mathrm{EAE}$ brown Norway rats. S1P1 receptor is widely expressed on the central nervous system cells. ${ }^{28,29}$ Our results revealed a high density of $\mathrm{S} 1 \mathrm{P} 1^{+}$cells in the ON of EAE animals and in the spinal cord of both healthy and EAE

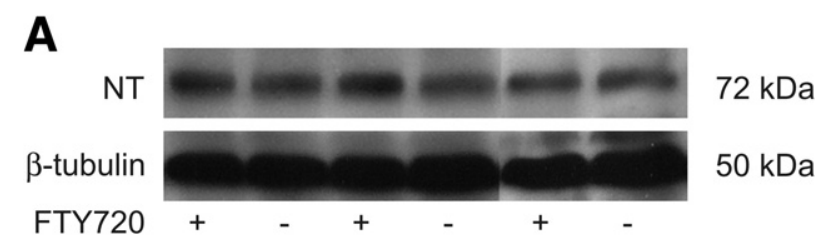

B

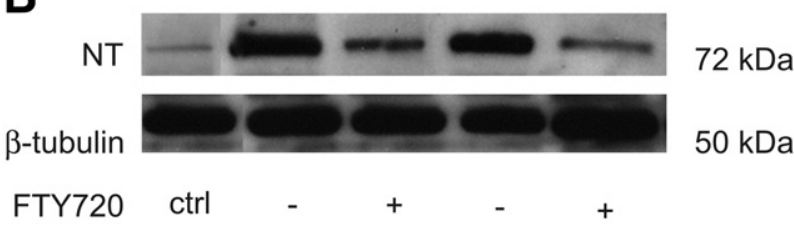

C

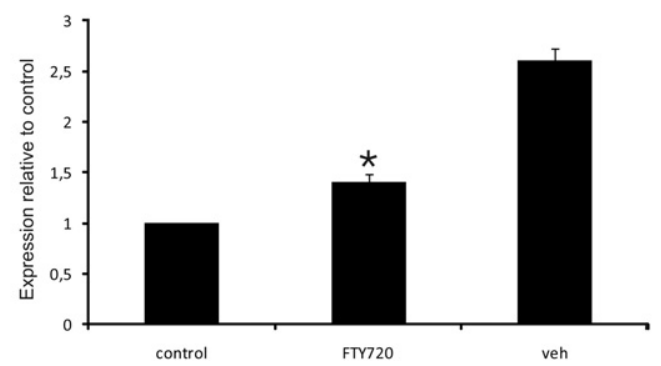

Figure 4. Nitrotyrosine (NT) expression. In Western blot analysisthe nitrotyrosine level in the retina (A) was unchanged, but in the optic nerve (B) the level was decreased in FTY720-treated animals $(+)$, compared with vehicletreated animals $(-)$. $\beta$-Tubulin serves as a housekeeping protein. C: Quantitation of nitrotyrosine expression level in the optic nerve. ${ }^{*} P<0.05$, compared with vehicle-treated animals. 

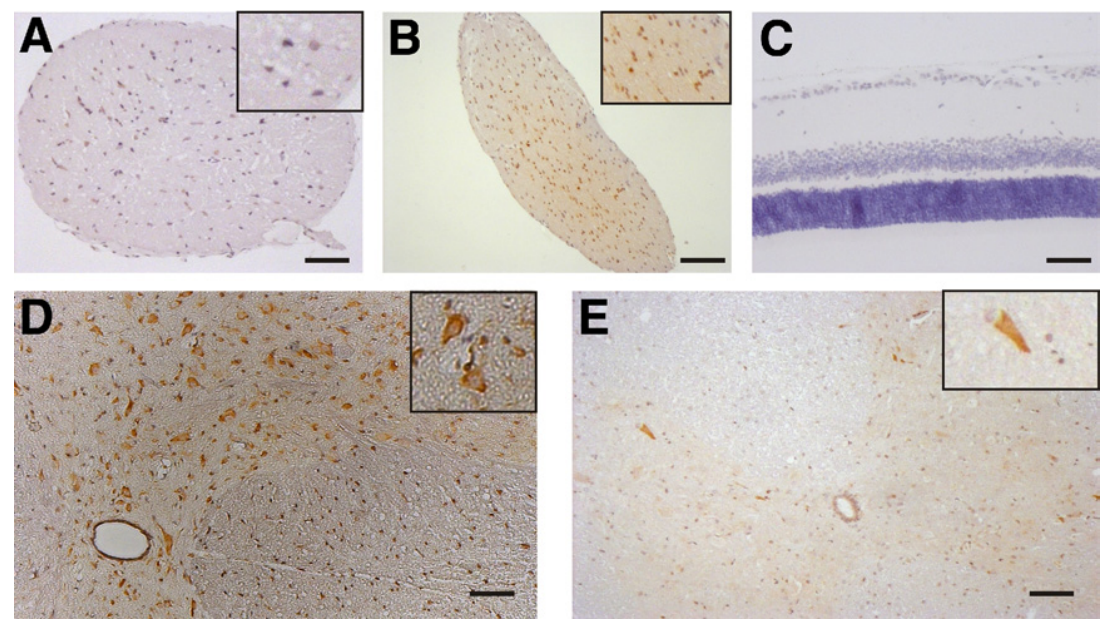

Figure 5. Immunohistochemistry for the S1P1-receptor. In comparison of S1P1-receptor expression pattern between healthy and MOG-EAE animals, no expression was found in optic nerve $(\mathbf{A})$ or retina $(\mathbf{C})$ of healthy animals, but strong S1P1 expression was evident in diseased optic nerve (B), as well as in both healthy (D) and diseased (E) spinal cord. Scale bars: $100 \mu \mathrm{m}(\mathbf{A}-\mathbf{C}) ; 20 \mu \mathrm{m}$ (D and E). Insets: matching higher magnification view of S1P1-receptor-negative (A) and S1P1-receptor-positive (B, D and E) cells.

animals. In contrast, no S1P1 ${ }^{+}$cells were observed in the retina and ON of healthy rats (Figure 5).

\section{Similar Activation of Apoptotic Signaling}

FTY720 treatment had no effect on protein levels of the anti-apoptotic protein Bcl-2 or of Bax (the pro-apoptotic member of the Bcl-2 family) in retinal cell lysates harvested at first clinical signs (EAE day 1$)(P=0.26$ for $\mathrm{Bcl}$ and $P=$ 0.33 for Bax) (Figure 6B). Further Western blot analyses of phosphorylation levels of Akt and MAPK 1/2 revealed no change in phosphorylation in FTY720-treated animals, compared with the vehicle-treated group $(P=0.37$ for pAkt; PMAPK was not detectable). Thus, we observed no influence of FTY720 on these signaling cascades, which we had previously identified as involved in the degeneration of RGCs in MOG-induced optic neuritis. ${ }^{16,18,30}$

\section{A}

MAPK

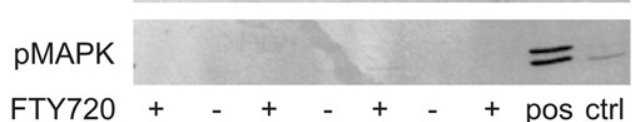

B

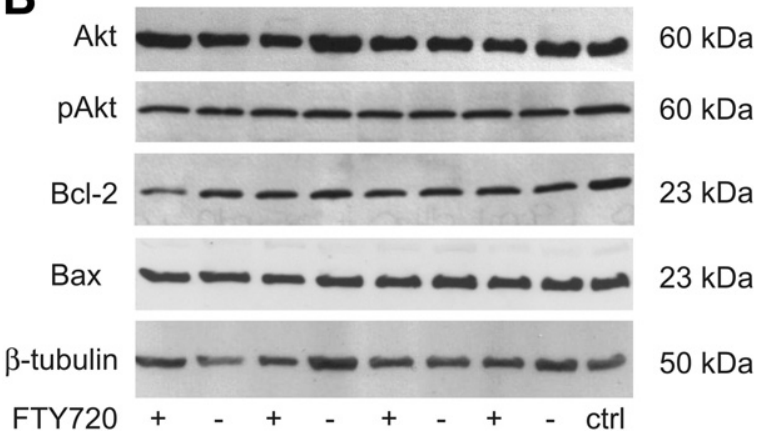

Figure 6. Western blot analysis. Western blots of retinal protein lysates obtained on the day of clinical manifestation of MOG-EAE revealed that FTY720 treatment $(+)$ resulted in unchanged protein levels of $\mathrm{Bcl}-2$ and $\mathrm{Bax}$, compared with treatment with vehicle alone (-). Analyses of phosphorylation levels of Akt and MAPK $1 / 2$ also revealed unchanged protein expression. $\beta$-Tubulin serves as a housekeeping protein.

\section{Expression of Cytokines and Neurotrophins}

To determine the effect of FTY720 treatment on the inflammatory milieu in the $\mathrm{ON}$, the expression pattern of cytokines and neurotrophic factors was evaluated using enzyme-linked immunosorbent assay and Luminex analyses of ON protein lysates. Interleukin 12 (IL-12), transforming growth factor $\beta 1$ (TGF- $\beta 1$ ), and tumor necrosis factor- $\alpha$ (TNF- $\alpha$ ) were analyzed based on the role of these cytokines in neuroprotection and neurodegeneration. $^{8,31-33}$ Levels of IL-12, TGF- $\beta 1$, and TNF- $\alpha$ showed no significant differences between FTY720- and vehicletreated animals (Figure 7). Luminex detection assays were used to measure levels of IL-18, TIMP-1, and ICAM-1 in ON protein lysates; all three cytokines are involved in S1P-receptor-induced T-cell migration. ${ }^{34} \mathrm{~A}$ higher level of ICAM-1 was found in the FTY720-treated group, compared with vehicle-treated animals, whereas similar levels of the other cytokines were present in ON lysates of rats with or without FTY720 treatment (Table 3).

\section{FTY720 Does Not Induce Neuronal Apoptosis under in Vitro or in Vivo Conditions}

To further investigate the effects of FTY720 on apoptosis of RGCs, we tested the direct effect of phosphorylated FTY720 (pFTY720) on RGCs in an immunopurified primary

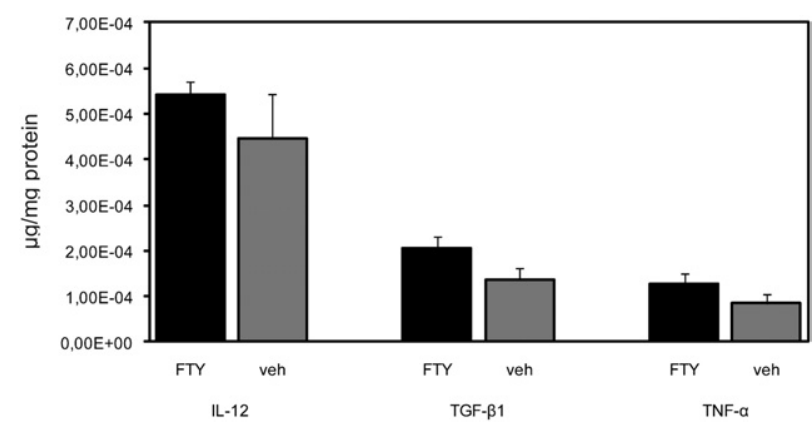

Figure 7. Enzyme-linked immunosorbent assay analysis of the expression pattern of neuroprotective cytokines and neurotrophins in the ON under influence of FTY720. Levels of IL-12, TGF- $\beta 1$, and TNF- $\alpha$ were similar in ON lysates of the FTY720- and vehicle-treated animals ( $n=10$ in each group). 
Table 3. Luminex Detection Assays Indicate Significant Increase Only in ICAM-1 Under FTY720 Treatment

\begin{tabular}{ccccc}
\hline $\begin{array}{c}\text { Animal } \\
\text { group }\end{array}$ & $\begin{array}{c}\text { ICAM-1 } \\
(\mathrm{ng} / \mathrm{mg})\end{array}$ & $\begin{array}{c}\mathrm{IL}-1 \beta \\
(\mathrm{ng} / \mathrm{mg})\end{array}$ & $\begin{array}{c}\mathrm{IL}-18 \\
(\mathrm{ng} / \mathrm{mg})\end{array}$ & $\begin{array}{c}\mathrm{TIMP}-1 \\
(\mathrm{ng} / \mathrm{mg})\end{array}$ \\
\hline FTY720 & $12 \pm 1$ & $0.08 \pm 0.05$ & $2.3 \pm 0.4$ & $6.4 \pm 1.5$ \\
Vehicle & $7 \pm 0.7$ & $0.05 \pm 0.02$ & $1.4 \pm 0.2$ & $5.1 \pm 0.9$ \\
$P$ value & $0.008^{*}$ & 0.41 & 1.0 & 0.95 \\
\hline
\end{tabular}

Assay was performed on optic nerve lysates on day 1 of MOG-EAE.

Data are reported as means $\pm \operatorname{SEM}(n=10)$.

${ }^{*} P<0.05$ is considered to be statistically significant.

cell culture. Cell viability was determined by MTT assay for pFTY720 in different concentrations with or without growth factor withdrawal. The number of surviving RGCs did not change in response to PFTY720 at concentrations up to 30 $\mu \mathrm{mol} / \mathrm{L}$, compared with cells cultured in pFTY720-free growth medium (Figure 8, A and B). These experiments were repeated three times, with similar results observed.

To test whether FTY720 has a detrimental effect on RGCs in healthy animals in vivo, rats were sham-immunized with complete Freund's adjuvant. Animals were treated daily with FTY720 for 21 days from the day of immunization. On day 21, retinas from FTY720-treated animals showed cell counts of $2426.3 \pm 137.79$ RGC/ $\mathrm{mm}^{2}(n=10)$, which did not differ significantly from previously described control counts of healthy animals treated with physiological salt solution (2567 \pm 89 RGC/ $\left.\mathrm{mm}^{2} ; n=10 ; P=0.4\right) .{ }^{35}$ To rule out a neurotoxic effect of FTY720 occurring only in EAE, we performed TUNEL staining on retinal sections. Here, we found no difference in the quantity of TUNEL-positive RGCs per section in both treatment groups ( $3 \pm 0.3 \mathrm{RGCs} /$ section in the vehicle treatment group and $3.9 \pm 0.5 \mathrm{RGCs} /$ section in the FTY720 treatment group; $n=9$ in each group; $P=0.1$ ).

\section{Discussion}

Using a rat model of autoimmune optic neuritis, we investigated the effects of the S1P receptor agonist FTY720, which has been shown to have significant antiinflammatory effects in MS clinical trials. ${ }^{5,6,36,37}$ In the present study, FTY720 treatment clearly resulted in a suppression of clinical disability associated with EAE and significantly reduced pathological changes related to optic neuritis. Nonetheless, even though inflammation, demyelination, and axonal damage in the ONs were substantially decreased, FTY720 did not prevent RGC death, which corresponded with a decline in visual function. Ongoing apoptosis of RGCs was the result of pro-apoptotic signaling that occurred in FTY720-treated rats to a similar extent as in vehicle-treated controls. We detected an up-regulation of ICAM-1 within the ON of FTY720treated rats, consistent with continuous neurodegeneration in the presence of substantial reduction of inflammation and demyelination. Inflammatory cells are known to be the major source of reactive oxygen and nitrogen species, which contribute to the neurodegeneration. 25,26 In agreement with the reduced numbers of inflammatory cells, we found that the nitrotyrosine level in the optic nerve decreased under FTY720 treatment. Neuronal loss was unchanged, however, even though FTY720 reduced the accumulation of oxidative stress in this model of autoimmune optic neuritis.

In several previous MS animal models, FTY720 showed convincing efficacy in terms of clinical deficits, with reduction of inflammatory cell infiltration ( $T$ cells, B cells, and macrophages) and reduced demyelination in spinal cord lesions, as well as in the ON. 8,9,12,38 In the present study, we confirmed the anti-inflammatory mode of action of FTY720 by lymphopenia. We also observed a substantial reduction in inflammation, demyelination, and axonal damage in the $\mathrm{ON}$, even though visual function was not affected by FTY720 application, compared with the control group. For formation of VEPs in the visual cortex, functional neuronal cell bodies in the retina and intact axons in the $\mathrm{ON}$ are both required. ${ }^{24}$ Therefore, RGC death without axon damage can cause a decline in visual function as measured by VEP recordings even in the absence of obvious structural changes in the optic nerve. ${ }^{16}$ The inability to prevent loss of visual function as measured by VEPs in animals treated with FTY720 is consistent with death of RGCs. From this observation, we conclude that neuronal loss is the reason for the lack of improvement in visual function in MOG-EAE in brown Norway rats treated with FTY720.

In context of neuroprotective immunity, it has been reported that immune cells produce several neuroprotective mediators, such as nerve growth factor (NGF) and glial cell line-derived neurotrophic factor (GDNF), which in turn activate a variety of protective intracellular neuronal pathways. ${ }^{39-41}$ Our previous studies support this hypothesis, showing that immunomodulatory treatment
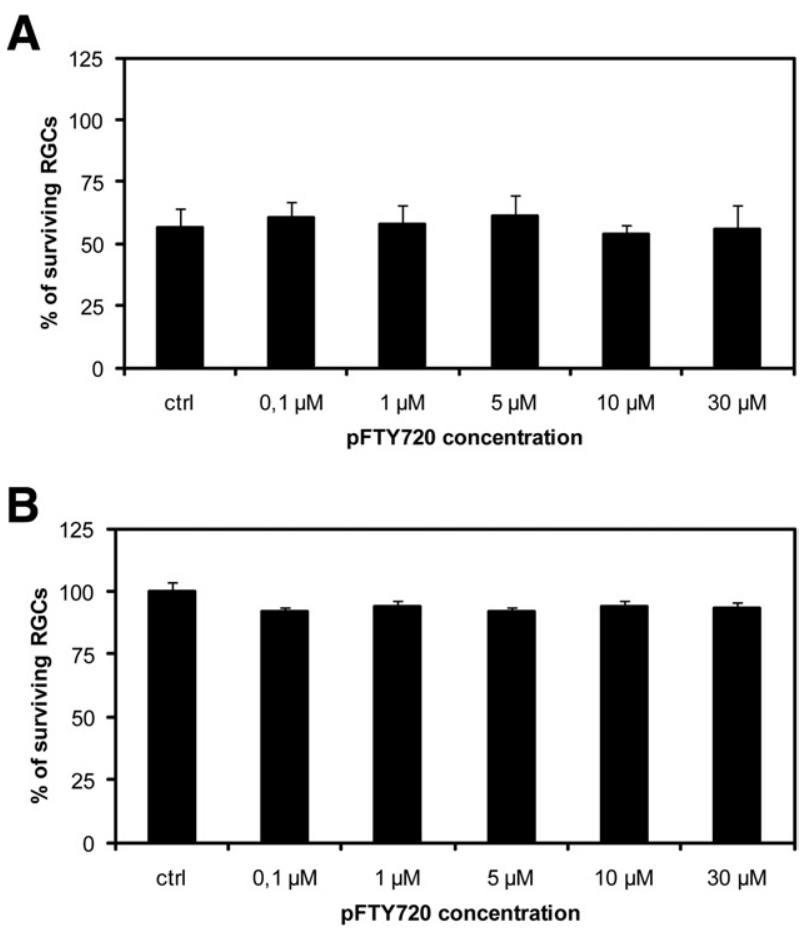

Figure 8. pFTY 720 had no direct influence on RGC survival in vitro in cell culture with (A) or without $(\mathbf{B})$ growth factor withdrawal. The numbers of surviving immunopurified RGCs treated with different concentrations of pFTY720 are expressed as a percentage of the matching control. 
with interferon- $\beta$ did not have substantial effects on the survival of RGCs. ${ }^{17,22}$ Anti-inflammatory treatment with methylprednisolone even increased apoptosis of RGCs during optic neuritis by inhibition of MAPK phosphorylation, although inflammatory infiltration of the ON was reduced. ${ }^{33}$ This pro-apoptotic effect of steroid treatment could be antagonized by simultaneous treatment with the neurotrophic factor erythropoietin. ${ }^{27}$ In a recent study, we found that FTY720 treatment combined with daily Epo treatment increased RGCs survival to within the same range as the cell density under Epo monotherapy. ${ }^{18}$ Our present results indicate that RGC survival is based mainly on the Epo effect alone, and its neuroprotective effect was not influenced by FTY720 treatment. Together with our in vitro data, these observations rule out a neurotoxic adverse effect for FTY720. Therefore, a neuronal and axonal protective effect in EAE might be expected from substances that target inflammation and neurodegeneration simultaneously. This property has been demonstrated to a certain extent for glatiramer acetate and minocycline in EAE, if treatment is initiated at the day of immunization. ${ }^{17,42}$

Because anti-inflammatory effects of FTY720 could not protect RGCs from cell death, we hypothesize that FTY720 shifts the inflammatory milieu toward neurotoxicity, resulting in a down-regulation of neuroprotective cytokines and neurotrophins and in a relative up-regulation of neurotoxic cytokines with a persistent activation of apoptotic signaling in RGCs. In analysis of the cytokine profile involved in neuronal survival during autoimmune inflammation, we found an up-regulation of ICAM-1 in ON lysates under FTY720 treatment. The profile of others candidate molecules remained unchanged, despite massive reduction of inflammatory infiltrates indicating possible immunomodulatory effect of FTY720. This hypothesis is supported by a recent study showing that FTY720 treatment did not have any effect on the gene expression of several cytokines, despite massive reduction of inflammatory infiltrates in the spinal cord of MOG-EAE rats. ${ }^{43}$ Presumably, the retention of most lymphocytes in the lymph nodes is the reason for a substantial reduction of inflammatory infiltrates also in the ONs. We hypothesize that a more pronounced activation of each individual inflammatory cell in the $\mathrm{ON}$ is the reason why the levels of pro-inflammatory cytokines in rats treated with FTY720 were comparable to the vehicle-treated group; however, further studies are needed to elucidate whether FTY720 action may additionally involve immunomodulation.

A detrimental effect of ICAM-1 on neuronal survival has been demonstrated in models of peripheral nerve axotomy and diabetic retinopathy, ${ }^{44,45}$ and treatment with monoclonal antibodies directed against ICAM-1 resulted in an improvement of neurological function and in a reduction of infarct volume in animal models of cerebral ischemia. ${ }^{46,47}$ However, FTY720 did not promote RGC cell death in vitro or in sham-immunized rats in vivo, suggesting that S1P receptor agonists do not have a direct pro-apoptotic effect. This conclusion is also supported by the unchanged quantity of apoptotic RGCs under FTY720 treatment observed with TUNEL staining.
Recently it has been shown that ICAM-1 is involved in S1P-receptor induced inhibition of T-cell migration. ${ }^{34}$ This is in agreement with our findings of an up-regulation of ICAM-1 by FTY720, which exerts its effect through the S1P-receptor. Moreover, we found an increased expression of S1P1 receptors in the ON in MOG-EAE animals, compared with healthy controls. The S1P1 receptor could not be detected In retinal sections; however, we cannot rule out signaling through other S1P receptors. Previous in vitro studies on signal transduction cascades induced by FTY720 have shown MAPK phosphorylation in astrocytes via S1P receptors and protection from apoptosis. ${ }^{10}$ In addition, a time-dependent modulation of $\mathrm{S} 1 \mathrm{P}$ receptor and a direct cytoprotective effect on oligodendrocyte progenitors have been observed with activation of MAPK $1 / 2$ and Akt. ${ }^{48,49}$ We therefore investigated whether the shift in the inflammatory response induced by FTY720 has any effect on the intracellular signaling cascades that we had previously identified as involved in the degeneration of RGCs in MOG-induced optic neuritis. ${ }^{16,18,30}$ No differences in protein expression of $\mathrm{Bcl}-2$, Bax, phosphorylated Akt and Akt, and phospho-MAPK 1/2 and MAPK 1/2 were observed in FTY720-treated rats, compared with the control group. In the absence of increased pro-apoptotic signaling after FTY720 treatment in retinal protein lysates obtained from rats with MOG-induced optic neuritis, an in vivo primary or secondary neurotoxic side effect of this anti-inflammatory agent can be disregarded. Furthermore, a primarily neurotoxic effect of FTY720 treatment without autoimmune inflammation was excluded by unchanged RGC densities in sham-immunized rats treated with FTY720.

In clinical trials, primarily anti-inflammatory therapy strategies such as alemtuzumab, daclizumab, and bone marrow transplantation effectively reduced present inflammatory activity, documented as reduced numbers of gadolinium enhancing lesions in magnetic resonance imaging in MS patients. ${ }^{50-52}$ However, these therapeutic strategies failed to reduce disease progression, indicating that at later disease stages the inflammatory activity is not directly correlated with accumulating clinical deficits. We hypothesize that the reason for increasing disability in these patients is ongoing neurodegeneration. In accord with this hypothesis, in the present study we observed ongoing loss of RGCs in rats with optic neuritis, even though inflammation and demyelination in the ONs was substantially improved by FTY720. Strong anti-inflammation itself was not sufficient to exert neuroprotective effects, in accordance to what we observed in previous EAE studies. ${ }^{18,30,35}$ Thus, our results support the notion that only the combination of agents that act synergistically on inflammation and neurodegeneration may reduce long-term disability in patients. Moreover, as a novel finding in the present study, FTY720 does not prevent neuronal apoptosis in an animal model reflecting neurodegenerative aspects of MS. Given that neurodegeneration in the early stages of MS is difficult to detect but is the reason for progressive functional deficits in later disease stages, the present MOG-EAE findings highlight the necessity for specifically evaluating the effects of FTY720 on neurodegeneration in 
MS patients, in addition to its well documented antiinflammatory properties.

\section{Acknowledgments}

We thank Britta Kaltwasser, Ina Boger, and Birte Könnecke for providing excellent technical support.

\section{References}

1. Trapp BD, Peterson J, Ransohoff RM, Rudick R, Mörk S, Bö L: Axonal transection in the lesions of multiple sclerosis. N Engl J Med 1998 338:278-285

2. Meyer R, Weissert R, Diem R, Storch MK, de Graaf KL, Kramer B, Bähr M: Acute neuronal apoptosis in a rat model of multiple sclerosis. J Neurosci 2001, 21:6214-6220

3. Kornek B, Storch MK, Weissert R, Wallstroem E, Stefferl A, Olsson T, Linington C, Schmidbauer M, Lassmann H: Multiple sclerosis and chronic autoimmune encephalomyelitis: a comparative quantitative study of axonal injury in active, inactive, and remyelinated lesions Am J Pathol 2000, 157:267-276

4. Brex PA, Ciccarelli O, O'Riordan JI, Sailer M, Thompson AJ, Miller DH: A longitudinal study of abnormalities on MRI and disability from multiple sclerosis. N Engl J Med 2002, 346:158-164

5. Cohen JA, Barkhof F, Comi G, Hartung HP, Khatri BO, Montalban X, Pelletier J, Capra R, Gallo P, Izquierdo G, Tiel-Wilck K, de Vera A, Jin J, Stites T, Wu S, Aradhye S, Kappos L; TRANSFORMS Study Group: Oral fingolimod or intramuscular interferon for relapsing multiple sclerosis. N Engl J Med 2010, 362:402-415

6. Kappos L, Radue EW, O'Connor P, Polman C, Hohlfeld R, Calabresi P, Selmaj K, Agoropoulou C, Leyk M, Zhang-Auberson L, Burtin P; FREEDOMS Study Group: A placebo-controlled trial of oral fingolimod in relapsing multiple sclerosis. N Engl J Med 2010, 362:387-401

7. Webb M, Tham CS, Lin FF, Lariosa-Willingham K, Yu N, Hale J, Mandala S, Chun J, Rao TS: Sphingosine 1-phosphate receptor agonists attenuate relapsing-remitting experimental autoimmune encephalitis in SJL mice. J Neuroimmunol 2004, 153:108-121

8. Fujino M, Funeshima N, Kitazawa Y, Kimura H, Amemiya H, Suzuki S, Li XK: Amelioration of experimental autoimmune encephalomyelitis in Lewis rats by FTY720 treatment. J Pharmacol Exp Ther 2003, 305: 70-77

9. Foster CA, Mechtcheriakova D, Storch MK, Balatoni B, Howard LM, Bornancin F, Wlachos A, Sobanov J, Kinnunen A, Baumruker T: FTY720 rescue therapy in the dark agouti rat model of experimental autoimmune encephalomyelitis: expression of central nervous system genes and reversal of blood-brain-barrier damage. Brain Pathol 2009, 19:254-266

10. Osinde M, Mullershausen F, Dev KK: Phosphorylated FTY720 stimulates ERK phosphorylation in astrocytes via S1P receptors. Neuropharmacology 2007, 52:1210-1218

11. Baumruker T, Billich A, Brinkmann V: FTY720, an immunomodulatory sphingolipid mimetic: translation of a novel mechanism into clinical benefit in multiple sclerosis. Expert Opin Investig Drugs 2007, 16: 283-289

12. Balatoni B, Storch MK, Swoboda EM, Schönborn V, Koziel A, Lambrou GN, Hiestand PC, Weissert R, Foster CA: FTY720 sustains and restores neuronal function in the DA rat model of MOG-induced experimental autoimmune encephalomyelitis. Brain Res Bull 2007, 74:307-316

13. Iglesias A, Bauer J, Litzenburger T, Schubart A, Linington C: T- and B-cell responses to myelin oligodendrocyte glycoprotein in experimental autoimmune encephalomyelitis and multiple sclerosis. Glia 2001, 36:220-234

14. Gold R, Linington $\mathrm{C}$, Lassmann $\mathrm{H}$ : Understanding pathogenesis and therapy of multiple sclerosis via animal models: 70 years of merits and culprits in experimental autoimmune encephalomyelitis research. Brain 2006, 129:1953-1971

15. Storch MK, Stefferl A, Brehm U, Weissert R, WallströM E, Kerschensteiner $\mathrm{M}$, Olsson $\mathrm{T}$, Linington $\mathrm{C}$, Lassmann $\mathrm{H}$ : Autoimmunity to myelin oligodendrocyte glycoprotein in rats mimics the spectrum of multiple sclerosis pathology. Brain Pathol 1998, 8:681-694
16. Hobom M, Storch MK, Weissert R, Maier K, Radhakrishnan A, Kramer B, Bähr M, Diem R: Mechanisms and time course of neuronal degeneration in experimental autoimmune encephalomyelitis. Brain Pathol 2004, 14:148-157

17. Maier K, Kuhnert AV, Taheri N, Sättler MB, Storch MK, Williams SK, Bähr M, Diem R: Effects of glatiramer acetate and interferon-beta on neurodegeneration in a model of multiple sclerosis: a comparative study. Am J Pathol 2006, 169:1353-1364

18. Sättler MB, Merkler D, Maier K, Stadelmann C, Ehrenreich H, Bähr M, Diem R: Neuroprotective effects and intracellular signaling pathways of erythropoietin in a rat model of multiple sclerosis. Cell Death Differ 2004, 11 Suppl 2:S181-192

19. Chaudhuri A, Hallett PE, Parker JA: Aspheric curvatures, refractive indices and chromatic aberration for the rat eye. Vision Res 1983 23:1351-1363

20. Brinkmann V, Davis MD, Heise CE, Albert R, Cottens S, Hof R, Bruns C, Prieschl E, Baumruker T, Hiestand P, Foster CA, Zollinger M, Lynch KR. The immune modulator FTY720 targets sphingosine 1-phosphate receptors. J Biol Chem 2002, 277:21453-21457

21. Zemann B, Kinzel B, Müller M, Reuschel R, Mechtcheriakova D, Urtz $\mathrm{N}$, Bornancin F, Baumruker T, Billich A. Sphingosine kinase type 2 is essential for lymphopenia induced by the immunomodulatory drug FTY720. Blood. 2006, 107:1454-1458

22. Sättler MB, Demmer I, Williams SK, Maier K, Merkler D, Gadjanski I, Stadelmann C, Bähr M, Diem R: Effects of interferon-beta-1a on neuronal survival under autoimmune inflammatory conditions. Exp Neurol 2006, 201:172-181

23. Brinkmann V, Cyster JG, Hla T: FTY720: sphingosine 1-phosphate receptor-1 in the control of lymphocyte egress and endothelial barrier function. Am J Transplant 2004, 4:1019-1025

24. Fiorentini A, Maffei L, Pirchio M, Spinelli D, Porciatti V: The ERG in response to alternating gratings in patients with diseases of the peripheral visual pathway. Invest Ophthalmol Vis Sci 1981, 21 : 490-493

25. Smith $\mathrm{KJ}$, Lassmann $\mathrm{H}$ : The role of nitric oxide in multiple sclerosis Lancet Neurol 2002, 1:232-241

26. Smith KJ, Kapoor R, Felts PA: Demyelination: the role of reactive oxygen and nitrogen species. Brain Pathol 1999, 9:69-92

27. Diem R, Sättler MB, Merkler D, Demmer I, Maier K, Stadelmann C, Ehrenreich $\mathrm{H}$, Bähr $\mathrm{M}$ : Combined therapy with methylprednisolone and erythropoietin in a model of multiple sclerosis. Brain 2005, 128 375-385

28. Klatt J, Hartung HP, Hohlfeld R: FTY720 (Fingolimod) als neue Therapiemöglichkeit der Multiplen Sklerose [FTY720 (Fingolimod) as a new therapeutic option for multiple sclerosis]. German. Nervenarzt 2007 , 78:1200-1208

29. Herr DR, Chun J: Effects of LPA and S1P on the nervous system and implications for their involvement in disease. Curr Drug Targets 2007 8:155-167

30. Maier K, Rau CR, Storch MK, Sättler MB, Demmer I, Weissert R, Taheri N, Kuhnert AV, Bähr M, Diem R: Ciliary neurotrophic factor protects retinal ganglion cells from secondary cell death during acute autoimmune optic neuritis in rats. Brain Pathol 2004, 14:378-387

31. Sättler MB, Togni M, Gadjanski I, Sühs KW, Meyer N, Bähr M, Diem R: Strain-specific susceptibility for neurodegeneration in a rat model of autoimmune optic neuritis. J Neuroimmunol 2008, 193:77-86

32. Diem R, Meyer R, Weishaupt JH, Bahr M: Reduction of potassium currents and phosphatidylinositol 3-kinase-dependent AKT phosphorylation by tumor necrosis factor-(alpha) rescues axotomized retinal ganglion cells from retrograde cell death in vivo. J Neurosci 2001, 21:2058-2066

33. Diem R, Hobom M, Maier K, Weissert R, Storch MK, Meyer R, Bähr M: Methylprednisolone increases neuronal apoptosis during autoimmune CNS inflammation by inhibition of an endogenous neuroprotective pathway. J Neurosci 2003, 23:6993-7000

34. Ledgerwood LG, Lal G, Zhang N, Garin A, Esses SJ, Ginhoux F, Merad M, Peche H, Lira SA, Ding Y, Yang Y, He X, Schuchman EH, Allende ML, Ochando JC, Bromberg JS: The sphingosine 1-phosphate receptor 1 causes tissue retention by inhibiting the entry of peripheral tissue $T$ Iymphocytes into afferent lymphatics. Nat Immunol 2008, 9:42-53

35. Sättler MB, Williams SK, Neusch C, Otto M, Pehlke JR, Bähr M, Diem R: Flupirtine as neuroprotective add-on therapy in autoimmune optic neuritis. Am J Pathol 2008, 173:1496-1507 
36. O'Connor P, Comi G, Montalban X, Antel J, Radue EW, de Vera A, Pohlmann H, Kappos L; FTY720 D2201 Study Group: Oral fingolimod (FTY720) in multiple sclerosis: two-year results of a phase II extension study. Neurology 2009, 72:73-79

37. Kappos L, Antel J, Comi G, Montalban X, O'Connor P, Polman CH, Haas T, Korn AA, Karlsson G, Radue EW; FTY720 D2201 Study Group: Oral fingolimod (FTY720) for relapsing multiple sclerosis. N Engl J Med 2006, 355:1124-1140

38. Kataoka H, Sugahara K, Shimano K, Teshima K, Koyama M, Fukunari A, Chiba K: FTY720, sphingosine 1-phosphate receptor modulator, ameliorates experimental autoimmune encephalomyelitis by inhibition of T cell infiltration. Cell Mol Immunol 2005, 2:439-448

39. Vanderlocht J, Hellings N, Hendriks JJ, Stinissen P: Current trends in multiple sclerosis research: an update on pathogenic concepts. Acta Neurol Belg 2006, 106:180-190

40. Hammarberg H, Lidman O, Lundberg C, Eltayeb SY, Gielen AW, Muhallab S, Svenningsson A, Lindå H, van Der Meide PH, Cullheim S, Olsson T, Piehl F: Neuroprotection by encephalomyelitis: rescue of mechanically injured neurons and neurotrophin production by CNSinfiltrating T and natural killer cells. J Neurosci 2000, 20:5283-5291

41. Barnabé-Heider F, Miller FD: Endogenously produced neurotrophins regulate survival and differentiation of cortical progenitors via distinct signaling pathways. J Neurosci 2003, 23:5149-5160

42. Maier K, Merkler D, Gerber J, Taheri N, Kuhnert AV, Williams SK, Neusch C, Bähr M, Diem R: Multiple neuroprotective mechanisms of minocycline in autoimmune CNS inflammation. Neurobiol Dis 2007, 25:514-525

43. Papadopoulos D, Rundle J, Patel R, Marshall I, Stretton J, Eaton R, Richardson JC, Gonzalez MI, Philpott KL, Reynolds R: FTY720 ameliorates MOG-induced experimental autoimmune encephalomyelitis by suppressing both cellular and humoral immune responses. J Neurosci Res 2010, 88:346-359

44. Siebert $\mathrm{H}$, Brück W: The role of cytokines and adhesion molecules in axon degeneration after peripheral nerve axotomy: a study in different knockout mice. Brain Res 2003, 960:152-156
45. Shelton MD, Kern TS, Mieyal JJ: Glutaredoxin regulates nuclear factor kappa-B and intercellular adhesion molecule in Muller cells: model of diabetic retinopathy. J Biol Chem 2007, 282:1246712474

46. Zhang RL, Chopp M, Li Y, Zaloga C, Jiang N, Jones ML, Miyasaka M, Ward PA: Anti-ICAM-1 antibody reduces ischemic cell damage after transient middle cerebral artery occlusion in the rat. Neurology 1994 44:1747-1751

47. Bowes MP, Rothlein R, Fagan SC, Zivin JA: Monoclonal antibodies preventing leukocyte activation reduce experimental neurologic injury and enhance efficacy of thrombolytic therapy. Neurology 1995 , 45:815-819

48. Miron VE, Jung CG, Kim HJ, Kennedy TE, Soliven B, Antel JP: FTY720 modulates human oligodendrocyte progenitor process extension and survival. Ann Neurol 2008, 63:61-71

49. Coelho RP, Payne SG, Bittman R, Spiegel S, Sato-Bigbee C: The immunomodulator FTY720 has a direct cytoprotective effect in oligodendrocyte progenitors. J Pharmacol Exp Ther 2007, 323 : $626-635$

50. Rieckmann P; Multiple Sklerose Therapie Konsensus Gruppe (MSTKG) [Multiple Sclerosis Therapy Consensus Group (MSTKG)]: Immunmodulatorische Stufentherapie der Multiplen Sklerose Aktuelle Therapieempfehlungen (September 2006) [Escalating immunomodulatory therapy of multiple sclerosis. Update (September 2006)]. German. Nervenarzt 2006, 77:1506-1518

51. Metz I, Lucchinetti CF, Openshaw H, Garcia-Merino A, Lassmann H, Freedman MS, Atkins HL, Azzarelli B, Kolar OJ, Brück W: Autologous haematopoietic stem cell transplantation fails to stop demyelination and neurodegeneration in multiple sclerosis. Brain 2007, 130: $1254-1262$

52. Coles AJ, Cox A, Le Page E, Jones J, Trip SA, Deans J, Seaman S, Miller DH, Hale G, Waldmann H, Compston DA: The window of therapeutic opportunity in multiple sclerosis: evidence from monoclonal antibody therapy. J Neurol 2006, 253:98-108 